\title{
Helical UAV - an 'Aerial Screw' inspired conceptual design for a passively cooled UAV
}

\author{
Mim Kabir $^{1 *}$, and Emmanouil Bouzakis ${ }^{2}$ \\ ${ }^{1}$ German University of Technology in Oman (GUtech), Department of Engineering, Halban, \\ Sultanate of Oman \\ ${ }^{2}$ German University of Technology in Oman (GUtech), Department of Engineering, Halban, \\ Sultanate of Oman
}

\begin{abstract}
A fleet of aircraft thriving in the military, commercial as well as recreational industry of recent decades has been that of the 'Unmanned Aerial Vehicles (UAVs)', more commonly referred to as 'Drones'. Their versatility in structure and function suitable for a wide range of applications have drawn considerable interest from leading institutions, industries, and governmental organisations. However, owing to their electronic nature, UAVs have shown significant performance deterioration in high temperature environments. This has been limiting their service in hot climatic regions such as those of the Middle East. In this context, this project investigated on the challenges of operating UAVs in high ambient temperatures and corresponding solutions. Consequently, based on the literature research and primary knowledge of aerodynamics, heat transfer and properties of common materials, a conceptual design has been proposed for a passively cooled, payload-carrying quadcopter body. The technology involves utilizing sun-shielding, natural ventilation and cooling by heat sinks and thermal radiation. The design bears prominent resemblance to the 'Aerial Screw' designed by Leonardo da Vinci which served as an inspiration for the use of a helical structure in the vehicle body, the major heat shielding and distinguishing feature of the UAV. The design in its general layout has been constructed using AutoCAD software and presented with general evaluation, possible flaws, development methods and prospects for the concept.
\end{abstract}

\section{Introduction}

Flying has always been a fascination of man which aviation has brought to fruition. However, beyond recreation, the exercise of inquisitive minds, and the pages of literature and scrolls of ancient mythologies, aviation has had a prominent role in building economies and shaping past and modern civilizations. In addition to conventional aircraft, the air-transport industry has received contribution from a thriving category of aerial vehicles called 'Unmanned Aerial Vehicles (UAVs)' which are more commonly known as 'Drones'. Available in a variety of

\footnotetext{
*Mim Kabir: mimkabir.t@gmail.com
} 
shape, size, and function, they can be piloted remotely or allowed to operate automatically and/or autonomously. Their multitude of possibilities, flexibility in flight paths, operational readiness, and prospects of a cleaner environmental footprint as compared to conventional aircraft and automotive have drawn considerable interest from leading institutions, industries, and governmental organisations.

However, despite the advancements and versatility, UAVs in the modern era have been demonstrating considerable limitation when performing in hot environments. This vulnerability has been significantly influencing the operability of UAV services in hot climatic conditions such as those experienced in the Middle East. Hence, in order to support the study of enhancing UAV applications in hot regions, this research aimed at investigating the challenges of UAV operations in high ambient temperatures and possible solutions. An objective to propose a conceptual design of a payload carrying quadcopter body capable of withstanding extreme heat via passive cooling strategy had thus been defined.

The concept has been produced with the help of literature research on background concepts of UAVs, risks of flying UAVs in hot temperatures, generally used cooling strategies and primary analysis of heat transfer, airflow, and material properties. The passive cooling strategies that the design has been created to rely on in its current stage include sun protection, natural ventilation, cooling by conduction and thermal radiation. The structure encompasses a quadcopter configuration and bears prominent resemblance to Leonardo da Vinci's aerial vehicle based design, 'Aerial screw' [1]. Da Vinci's design influenced use of a helical structure intended to serve for natural ventilation and protection from sunlight which is the primary source of ambient heat in most outdoor circumstances. The design proposed in this document had been constructed with the help of a CAD software and presented with descriptions for the structure, material, and surface features. Discussion on the possible flaws and corresponding development methods that maybe considered have also been included.

The project has been restricted to the conceptual representation phase of the design with limited objectives and corresponding specifications to comply with the limited resources that had been available to carry out further research. As a result, attention had been given to demonstrate the primary establishment of passive cooling strategies into a typical payload carrying quadcopter body. However, future work for the project anticipates evaluation of structural, thermal, and aerodynamic aspects of the system using Finite Element Analysis (FEA) and Computational Fluid Dynamics (CFD).

\section{Literature Review}

\subsection{Challenges in Hot Environments and Solutions}

Owing to the electronic nature of UAVs, overheating has been one of the most inevitable problems faced by the vehicles when flown in high ambient temperatures. Additionally, their aerodynamic performance has also been negatively influenced as described in the following subsections.

\subsubsection{Overheating}

A rise in temperature increases the electrical resistance within the system's components which may lead to overheating; thus, potentially altering material properties such as strength [2] and raising a fire or explosion hazard. This may limit the duration of operation, versatility of operating conditions, hinder efficiency of performance of electronic components and overall system, risk wellness of payload and raise costs of structural maintenance. However, the heat produced from a system can be propagated away by regulating the flow of heat via 
conduction, convection, or radiation currents. Several basic systems which have been commonly in use to achieve avoidance and reduction of heat from a system include the following:

- Sun-shading barriers such as canopies in parking areas, window shields in cars, and heat shields in space vehicles.

- Passive ventilation systems such as louver panels installed in homes

- Air cooling systems such as exhaust fans prevalent in a wide range of applications

- Liquid cooling systems such as those used in condensing units of air conditioners

- Heat-sinks such as those found embedded within electronics

- Thermally radiative cooling systems which use reflective surfaces of materials for heat reflectance and dark surfaces of materials for heat emittance

\subsubsection{Reduced Lift}

An increased ambient air temperature also affects aerodynamics of the flight. A temperature elevation within a given volume of air with constant pressure, decreases the density of particles in the air [3, p. 94]. Thus, the overall pressure exerted by that particular volume air on a given surface area of the wing or rotor blade of an aircraft travelling at a given speed is lesser compared to that experienced prior to temperature elevation [3, p. 94]. Consequently, a reduction in the aerodynamic lift is achieved [3, p. 94]. This effect of reduced air pressure can be compensated by aircraft via operating at higher velocities [3, p 94] as a faster rotating propeller or aircraft body will be able to experience an increased air pressure on its surface to produce lift. In the case of a fixed-wing aircraft, the higher airspeed targeted for take-off can be provided by covering a longer horizontal distance. This, however, demands an increase in power consumption for both rotary and fixed-wing aircraft which may be supplied by utilizing multiple power sources. The payload borne by the aircraft can also be reduced to lower the overall weight and thus the amount of lift and corresponding speed needed for flight $[3$, p. 95].

\section{Design Concept and Overview}

In line with the defined objective of this project, the section 2.1.1 'Overheating', had been referred for possible solutions for overheating. These solutions were coupled with primary knowledge of aerodynamics alongside mechanical and heat transfer properties of common materials, to produce a conceptual design. The design demonstrates the general layout of the body and has been represented via illustrations created by constructing 3-D models of the design in the commercial Computer Aided Design (CAD) software named, 'AutoCAD'. The illustrations for the design in its final assembled form have been displayed in Fig. 1 via three different perspectives - 'Front view', 'North-isometric view' and 'South-isometric view'.

(a)

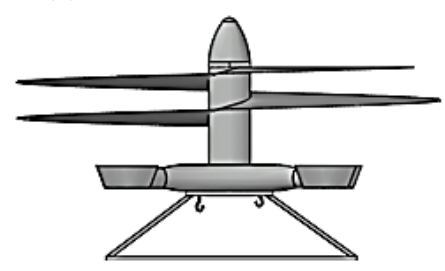

(b)

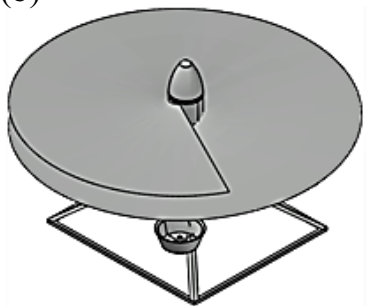

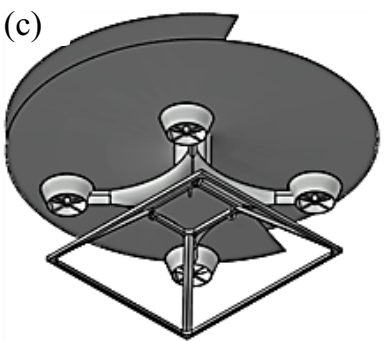

Fig. 1. (a) Final assembly (Front view), (b) Final assembly (North-isometric view) and (c) Final assembly (South-isometric view). 
The system comprises of five major structural elements which have been labelled in Fig.2. and individually illustrated in Fig.3.- Fig.7. within the following subsections. The illustrations for the individual components have been displayed via four different perspectives - 'Front and sectional view', 'North-isometric view', and 'South-isometric view' and have been accompanied by descriptions of the structure, material and surface characteristics proposed for each of the components. Possible flaws that may be encountered in general and corresponding compensation methods have been discussed as well.

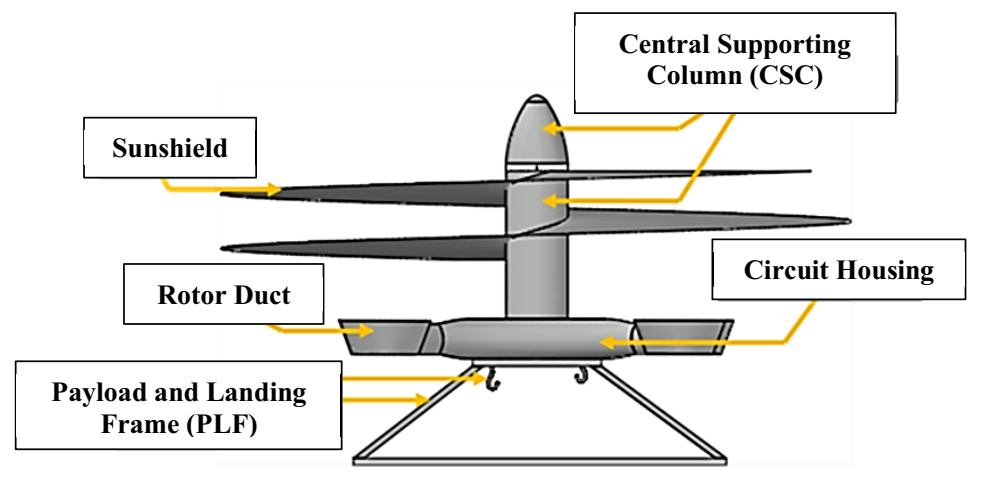

Fig. 2. Final assembly with labeling of major components.

\subsection{Structure}

\subsubsection{Circuit Housing}

(a)

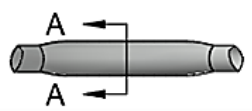

(b)

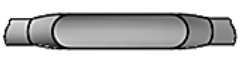

(c)

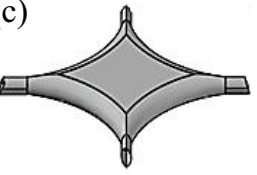

(d)

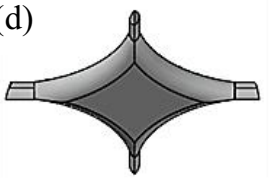

Fig. 3. (a) and (b) Circuit Housing (Front and sectional view). (c) Circuit Housing (Northisometric view). (d) Circuit Housing (South-isometric view).

The circuit housing may be an enclosed structure to accommodate and protect the internal electronic system from external harm causing elements like dust. It may have a ' + ' shaped appearance to support an exterior rotor system with a '+' shaped quadcopter configuration to maintain stability.

\subsubsection{Rotor Ducts}

(a)

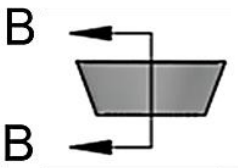

(b)

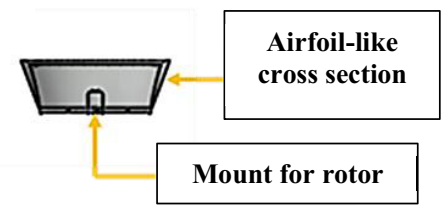

(c)

(d)

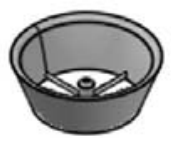

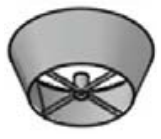

Fig. 4. (a) and (b) A single Rotor Duct (Front and sectional view). (c) A single Rotor Duct (North-isometric view). (d) A single Rotor Duct (South-isometric view). 
Four nozzle shaped ducts may be installed for four rotor systems. Each duct may possess an airfoil-like cross section to increase aerodynamic efficiency in terms of downward thrust and safety of user [4]. A mount within each duct may support placement of the rotor system.

\subsubsection{Sunshield}

(a)

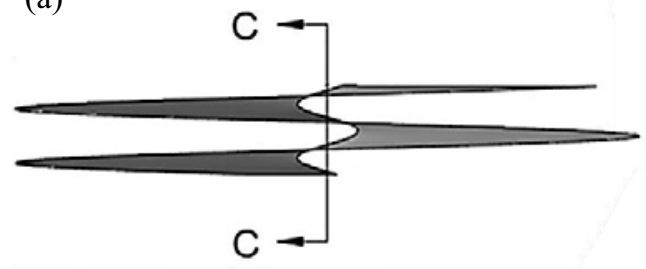

(b) (c)

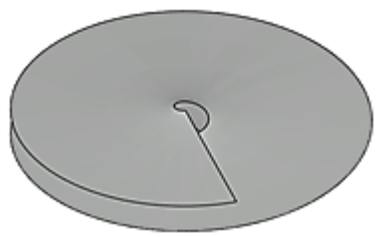

(d)

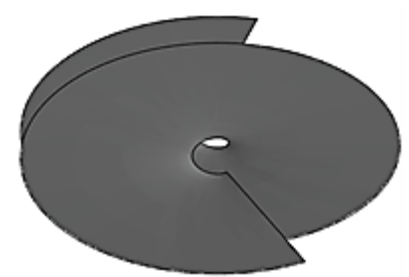

Fig. 5. (a) and (b) Sunshield (Front and sectional view). (c) Sunshield (North-isometric view). (d) Sunshield (South-isometric view).

The sunshield maybe a flat and static helical sheet to block sunlight but allow air circulation. The helical structure may allow the air to be driven in a spiralling motion from above to bottom of the system. Thus, lift, ventilation, and autorotation may be achieved in addition to sun protection.

\subsubsection{Central Supporting Column (CSC)}

(a)

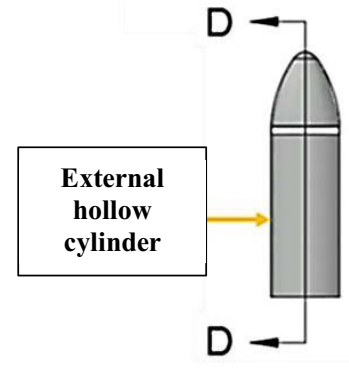

(b)

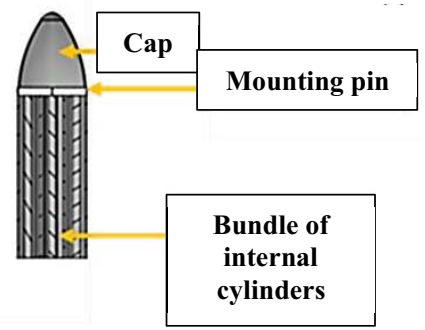

(c)

(d)
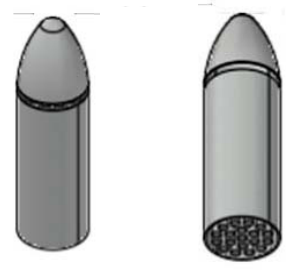

Fig. 6. (a) and (b) CSC (Front and sectional view). (c) CSC (North-isometric view). (d) CSC (South-isometric view).

The component may be divided into three structures, namely - external hollow cylinder, bundle of internal cylinders and cap. The multiple internal cylinders may act as heat sinks for the housing while being shielded from direct sunlight by the external cylinder. The roundedcone shaped cap on top may also shield the internal cylinders from sunlight while reducing downward drag forces. Each of the three structures may be placed at a certain distance from 
each other to avoid direct surface-contact and thus reduce heat transfer via conduction while allowing room for convection for cooling.

\subsubsection{Payload and Landing Frame (PLF)}

(a)

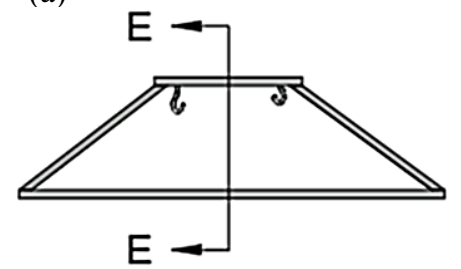

(b)

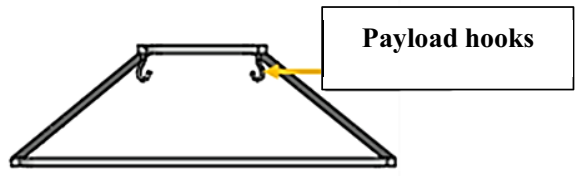

(d)

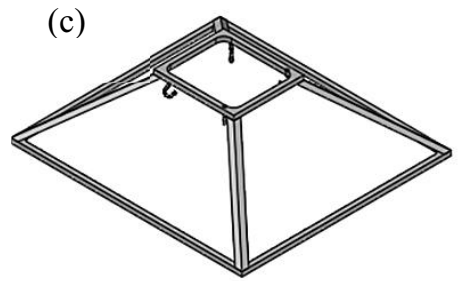

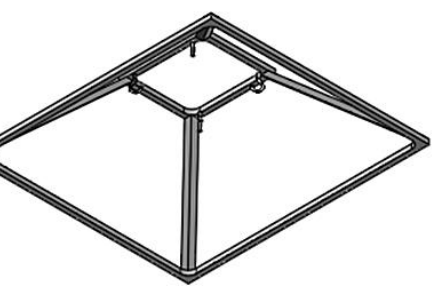

Fig. 7. (a) and (b) PLF (Front and sectional view). (c) PLF (North-isometric view). (d) PLF (South-isometric view).

The structure may possess a truncated pyramid configuration for stability. The top frame may support the housing and its adjacent structures while the bottom frame may act as a landing platform. Hooks may be connected to the four corners of the top frame to suspend the payload. The diagonal columns may also allow space for accommodating the payload in the center of the PLF.

\subsection{Material and Surface}

The basic characteristics of the materials and surfaces with respect to the different structures have been tabulated in Table 1 .

Table 1. Material and surface characteristics categorised by the corresponding structures

\begin{tabular}{|c|c|c|c|}
\hline & \multicolumn{3}{|c|}{ Structure } \\
\hline & $\begin{array}{l}\text { Circuit housing, rotor } \\
\text { ducts, internal cylinders } \\
\text { of CSC, and PLF }\end{array}$ & $\begin{array}{l}\text { External cylinder and } \\
\text { cap of CSC }\end{array}$ & Sunshield \\
\hline Material & $\begin{array}{l}\text { - Aluminum - high } \\
\text { thermal conductivity to } \\
\text { help absorb and release } \\
\text { internal heat to } \\
\text { surrounding. }\end{array}$ & $\begin{array}{l}\text { - Aluminum on outer } \\
\text { surface - highly } \\
\text { reflective to sunlight } \\
\text { • Styrofoam inner } \\
\text { surface - thermal } \\
\text { insulation for interior }\end{array}$ & $\begin{array}{l}\text { - Aluminum on top } \\
\text { surface - highly } \\
\text { reflective to sunlight } \\
\text { - Styrofoam on bottom } \\
\text { surface - thermal } \\
\text { insulation for housing }\end{array}$ \\
\hline Surface & $\begin{array}{l}\text { - Reflective and } \\
\text { conductive black paint } \\
\text { for outer and inner } \\
\text { surfaces - high thermal }\end{array}$ & $\begin{array}{l}\text { - Mirror finish on outer } \\
\text { metallic surface with no } \\
\text { coating }\end{array}$ & $\begin{array}{l}\text { - Mirror finish on } \\
\text { outer metallic surface } \\
\text { with no coating }\end{array}$ \\
\hline
\end{tabular}




\begin{tabular}{|c|c|c|c|}
\hline absorptivity and & & \\
emissivity of black & & \\
color may absorb and & & \\
release internal heat to & & \\
surrounding. & & \\
Reflectiveness may & & \\
avoid external heat & & \\
while conductivity may & & \\
encourage conduction & & \\
between paint and & & \\
Aluminum to maximize & & \\
heat sink efficiency. & & \\
\hline
\end{tabular}

\subsection{General Considerations}

The possible flaws of the proposed design as observed based on primary analysis has been listed in Table 2 along with possible ways to compensate for the impacts of the flaws.

Table 2. Possible flaws and methods to fix them

\begin{tabular}{|c|c|}
\hline Flaw & Fix \\
\hline Sunshield may only block vertical sunrays & $\begin{array}{c}\text { Sunshield may be mobile in its angular } \\
\text { position on the CSC along multiple axes. } \\
\text { Louver panels may also be attached along } \\
\text { the circumference of the lower section of } \\
\text { the sunshield to shroud the housing and } \\
\text { block sunlight but allow airflow. }\end{array}$ \\
\hline $\begin{array}{c}\text { Sunshield's aerodynamic features may } \\
\text { provide insufficient ventilation/lift }\end{array}$ & $\begin{array}{c}\text { Sunshield maybe rotational along the axial } \\
\text { direction of the CSC during flight }\end{array}$ \\
\hline $\begin{array}{c}\text { Forward flight motion maybe disrupted by } \\
\text { sunshield }\end{array}$ & $\begin{array}{c}\text { Design maybe optimized for smoother } \\
\text { edges of sunshield and reduced vertical } \\
\text { distance coverage. }\end{array}$ \\
\hline $\begin{array}{c}\text { Vertical distance coverage and weight of } \\
\text { sunshield and CSC may reduce stability } \\
\text { and lift }\end{array}$ & $\begin{array}{c}\text { Lighter material maybe investigated, and } \\
\text { vertical distance coverage of CSC and } \\
\text { sunshield may be reduced. }\end{array}$ \\
\hline $\begin{array}{c}\text { Pure Aluminum and Styrofoam material } \\
\text { pose mechanical risk }\end{array}$ & $\begin{array}{c}\text { Appropriate combination such as alloys } \\
\text { and/or composites of Aluminum and } \\
\text { Styrofoam may be investigated. }\end{array}$ \\
\hline $\begin{array}{c}\text { Black coating and Aluminum surface may } \\
\text { absorb more heat from outside than emit }\end{array}$ & $\begin{array}{c}\text { Appropriate cooling strategies may be } \\
\text { investigated to maintain positive } \\
\text { temperature gradient from material surface } \\
\text { to the ambient air. Specialized materials } \\
\text { providing radiative cooling during daytime } \\
\text { alongside nighttime may also be utilized } \\
\text { [5]. Frequency and duration of operation } \\
\text { may be regulated to avoid overheating due } \\
\text { to prolonged performance. }\end{array}$ \\
\hline
\end{tabular}




\section{Conclusion and Future Work}

Since the beginning of the $20^{\text {th }}$ century, UAVs have been serving in multiple applications in a versatile range of environments. However, operating in high ambient temperatures has been posing a significant challenge on the aircraft through its impact on several factors including aerodynamic efficiency, structural strength, wellness of system and payload, and thus overall operability and economic efficiency. Therefore, with the help of literature research and primary analysis, this study has proposed a conceptual design for the body of a payload carrying quadcopter, intending to provide the vehicle with the ability to operate in high ambient temperatures by utilizing passive cooling technologies to avoid overheating.

The concept has been represented by demonstrating the basic layout and key materials and describing the thermal protection strategies used which include sun-shielding, natural ventilation, and cooling by conduction, convection, and radiation technology. The possible flaws and potential methods of compensation have also been discussed. The research may be furthered in the future to analyse the impact of changes made to each of the different structures and optimised accordingly while taking into account any design constraints. The future work may be conducted using FEA and CFD analysis for evaluating the structural, thermal, and aerodynamic aspects of the proposed design with the help of CAD models.

The project has been presented with the goal to facilitate a foundation for possible design concepts that may contribute to the development of delivery-UAV systems capable of maintaining 'safe' temperatures of the system and payload, ultimately expanding their services in hot climatic regions such as that of the Middle East. If satisfactory outcomes are accomplished, the design study can be extended to be utilised in UAVs of diverse designs such fixed wing aircraft. Additionally, the concept may also be investigated in the context of the architectural industry to serve as helical sun-shielding barriers as a potential system to cool buildings in line with current sunshades and other architectural cooling strategies.

\section{References}

[1] M. P. Scholz, "The Aerial Screw," Advanced NXT, Apress, pp. 227-228 (2007) [Online]. Available: https://link.springer.com/chapter/10.1007/978-1-4302-0258-5_6 (accessed 2021)

[2] I. Martinez. "Thermal effects on materials.pdf," Isidoro Martinez [Online]. Available: http://webserver.dmt.upm.es/ isidoro/ot1/Thermal\%20effects\%20on\%20materials.pdf (accessed 2021)

[3] E. Coffel, R. Horton, "Climate Change and the Impact of Extreme Temperatures on Aviation," Weather Clim. Soc., vol. 7, pp. 94-95 (2015) [Online]. Available: https://journals.ametsoc.org/view/journals/wcas/7/1/wcas-d-14-00026_1.xml (accessed 2021)

[4] J. L. Pereira, "Hover and Wind-tunnel Testing of Shrouded Rotors for Improved Micro Air Vehicle Design," Ph.D. dissertation, Fac. Graduate School, Univ. Maryland, College Park, USA (2008) [Online]. Available: https://drum.lib.umd.edu/handle/1903/8752 (accessed 2021)

[5] B. Zhao, M. Hu, X. Ao, N. Chen, G. Pei, " Radiative cooling: A review of fundamentals, materials, applications, and prospects," Appl. Energy, vol. 236, pp. 489513 (2019) [Online]. Available: https://www.sciencedirect.com/science/article/pii/S0306261918318373 (accessed 2021) 